\title{
A COMPARATIVE STUDY OF FLURBIPROFEN AND ASPIRIN IN SOFT TISSUE TRAUMA
}

\author{
David S. MUCKLE, M.B., B.S., F.R.C.S., M.S. \\ Accident Service, Radcliffe Infirmary, Oxford \\ Surgeon and Medical Adviser to Oxford United F.C.
}

\begin{abstract}
A double blind study using flurbiprofen (2-(2-fluoro-4-biphenylyl propionic acid) $150 \mathrm{mg}$ daily and soluble aspirin (3.6 g daily) for $\mathbf{5}$ days immediately after injury, was carried out in $\mathbf{5 2}$ soft tissue injuries to the lower limb in professional sportsmen. Flurbiprofen was more effective than aspirin in producing analgesia (when daily pain scores were considered) after day $2(p<0.02)$; and flurbiprofen produced a more effective resolution of soft tissue trauma when days to training and match play were considered ( $p<0.05$ ). The inhibitory effects of flurbiprofen on prostaglandin biosynthesis and tissue action are mentioned and the use of anti-inflammatory agents given immediately after soft tissue injuries discussed.
\end{abstract}

\section{Introduction}

In a previous double blind study using a phenylalkanoic acid, "Brufen", (ibuprofen (2-(4-iso-butylphenyl) propionic acid) $1,200 \mathrm{mg}$ daily) and soluble aspirin (3.0 $g$ daily) it was shown that the immediate use of these anti-inflammatory agents was beneficial in resolving soft tissue trauma, with ibuprofen having a more significant action than aspirin (Muckle 1974). The possible action of these compounds in affecting prostaglandin biosynthesis and release was discussed.

A double blind trial of flurbiprofen (2-(2-fluoro-4biphenylyl) propionic acid) $150 \mathrm{mg}$ daily) and soluble aspirin ( $3.6 \mathrm{~g}$ daily) for 5 days immediately after injury was carried out in 52 soft tissue injuries to the lower limb in professional footballers at one club (Oxford United) during the season 1974-75. Thus the advantages or disadvantages of each compound could be assessed prospectively in terms of analgesia and recovery of the soft tissues from injury (as demonstrated by the period of return to training and match fitness).

Flurbiprofen was chosen because it is a potent inhibitor of prostaglandin synthetase, possesses antiinflammatory and analgesic properties, and has been shown in animal tests to be two hundred times more potent than acetylsalicylic acid and up to fifty times more potent than ibuprofen (Adams et al. 1975).

\section{Methods}

Immediately after a soft tissue injury to the lower limb the player received the standard therapy of cold compress, elastic or crepe support, and limb rest and elevation. In addition the player received a pack containing five days supply of either compound presented as white capsules. Each capsule contained $1.2 \mathrm{~g}$ aspirin or $50 \mathrm{mg}$ flurbiprofen. Three times each day, at the moment of taking each capsule, the player indicated the level of pain (mild, moderate or severe) according to instructions outlined on the jacket of the pack, and the appropriate square was marked. The injured area was observed daily by the trainer or club doctor and all signs recorded. The dates to full training and match fitness were noted.

The injuries were divided into two basic groups designated "trauma" and "sprains" as in the previous study (Muckle 1974).

\section{Results}

Fifty-one patients were admitted to the trial, twentysix on aspirin and twenty-five on flurbiprofen (one patient complained of sleepiness after the initial dose of flurbiprofen and therapy was stopped).

Table I shows that the distribution of the two basic injury groups between the two compounds was well balanced, and the numbers in each category were sufficient to allow a separate analysis for both direct trauma and sprains, when necessary. All patients were between the ages of 15 and 34 years and no separate analysis was made according to age groups.

Table I

Distribution of Patients in Each Injury Category

$\begin{array}{llll} & \text { Direct Trauma } & \text { Sprain } & \text { Total } \\ \text { Aspirin } & 13 & 13 & 26 \\ \text { Flurbiprofen } & 11 & 14 & 25 \\ & 24 & 27 & 51\end{array}$

Table II shows the analysis of pain scores as done by comparing the total daily pain score for all individuals in one treatment group with those in another treatment group, for each injury category. Because the pain scores 
for the two treatments were almost identical at the commencement of therapy, it was not necessary to look at the improvement of pain scores but merely the total pain score for one day. The total daily pain score was subjected to the Wilcoxon rank sum test.

\section{Table II}

\section{Analysis of Pain Scores}

day 1 day 2 day 3 day 4 day 5 day 6

$\begin{array}{lllllll}\text { Aspirin } & & & & & & \\ \text { Flurbi- } & 4.2 & 3.4 & 2.8 & 2.5 & 1.9 & 1.2 \\ \text { profen } & 4.1 & 2.6 & 1.6 & 1.3 & 0.6 & 0.3 \\ \text { p }<>0 . & >.05 & <.02 & <.01 & <.01 & <.01 & <.01\end{array}$

The analysis of pain scores (Table II) shows that patients taking flurbiprofen experienced significantly less pain $(p<0.01)$ at days 5 and 6 when both types of injuries were considered, and the pain scores were significantly lower in the flurbiprofen group from day 2 onwards $(p<0.02)$.

Tables IIIa and IIIb show the analysis of the number of days to the commencement of training, means and standard errors of the number of days given, and the square root transformation was used before doing the t-test. In all injury groups flurbiprofen was shown to be significantly better than aspirin (Flurbiprofen 3.38 days \pm 2.2 ; aspirin 4.27 days \pm 1.5$)(p<0.05)$.

Table IIIa

Analysis of Number of Days to Commencement of Training

Mean S.E.M. no. t. df. proba-

$\begin{array}{lrlllll}\text { Aspirin } & 4.27 & 1.5 & 26 & 2.14 & 48 & p<0.05 \\ \text { Flurbiprofen } & 3.38 & 2.2 & 24 & & & \end{array}$

\section{b. Number of players training in a given time}

$\begin{array}{llllll}\text { days: } & 1-3 & 4-6 & 7-9 & 10-12 & \text { no. } \\ \text { Aspirin } & 9(35 \%) & 16 & 1 & 0 & 26 \\ \text { Flurbiprofen } & 16(65 \%) & 6 & 1 & 1 & 24\end{array}$

Table IIIc shows the analysis of the number of days to match fitness, the same statistical method being applied. After flurbiprofen the player reached match fitness at 4.79 days \pm 3.1 , compared to aspirin 6.04 days $\pm 1.9(\mathrm{p}<0.05)$.

\section{c. Analysis of Number of Days to Match Fitness}

$\begin{array}{lllllll} & \text { Mean } & \text { S.E.M. } & \text { no. } & \text { t. } & \text { df. } & \begin{array}{l}\text { proba- } \\ \text { bility }\end{array} \\ \text { Aspirin r } 6.04 & 1.9 & 26 & 2.20 & 48 & p<0.05 \\ \text { Flurbiprofen } 4.79 & 3.1 & 3 & & & \end{array}$

(results not stated for one player on flurbiprofen)

\section{Discussion}

The speedy and effective resolution of soft tissue trauma is an ideal requisite for all involved in orthopaedic surgery, and yet there have been relatively few investigations into the use of anti-inflammatory agents to promote this aim. Non specific tissue damage will release prostaglandins (Andersen \& Ramwell 1974) (Figure 1) and prostaglandin $E_{1}$ has been implicated in increasing vascular permeability due to a direct action rather than through an intermediary response involving histamine or serotonin (Zurier 1974). Vane et al. (1971) has shown that aspirin and other non-steroid anti-inflammatory agents can inhibit both prostaglandin release and prostaglandin synthetase activity. Prostaglandins $E_{1}$ and $F_{1} a$ increase collagen biosynthesis and may be responsible for excessive scar formation after injury (Blumenkrantz and Sondergaard 1972).

Both aspirin ( $3 \mathrm{~g}$ daily) and ibuprofen (1200 mg daily) have been shown to be effective in resolving soft tissue injuries in professional sportsmen (Muckle 1974). In the present trial the activity of flurbiprofen and aspirin were compared in terms of analgesia and the effective resolution of the soft tissue injuries as denoted by a return to training and playing. The analysis of pain scores showed that flurbiprofen was more effective than aspirin thus allowing an earlier application of remedial therapy (e.g. static quadriceps exercises) and helping to combat muscle atrophy. This fact was clearly seen in an earlier return to training and match play (Table III).

Huskisson et al. (1973) compared indomethacin (50 $\mathrm{mg}$, thrice daily) with a placebo in soft-tissue trauma in footballers, and found that there was no difference between the two groups ( 30 players in all) when pain relief and resumption to training were studied - results that were contrary to those of Buelvas (1967) and Leclerc and Autissier (1969).

Looking at the present trial as a whole, flurbiprofen (150 $\mathrm{mg}$ daily) significantly reduces the period of pain, the time to the commencement of training, and the time taken to become match fit, compared to aspirin. Only one player complained of side effects, and routine screening of blood, liver function and renal tests did not show any abnormal results. Thus as an adjuvant therapy to immobilization of the injured area, flurbiprofen has a place in the treatment of soft-tissue trauma, provided that it is given within a short period after injury, when the local biochemical changes (including prostaglandin release) are being initiated.

\section{Acknowledgements}

I would like to thank the staff of Oxford United, especially the trainer Ken Fish; Dr Fiona Sheldrake for her interest and advice; and Andrew S. Woods who interpreted the statistics. 

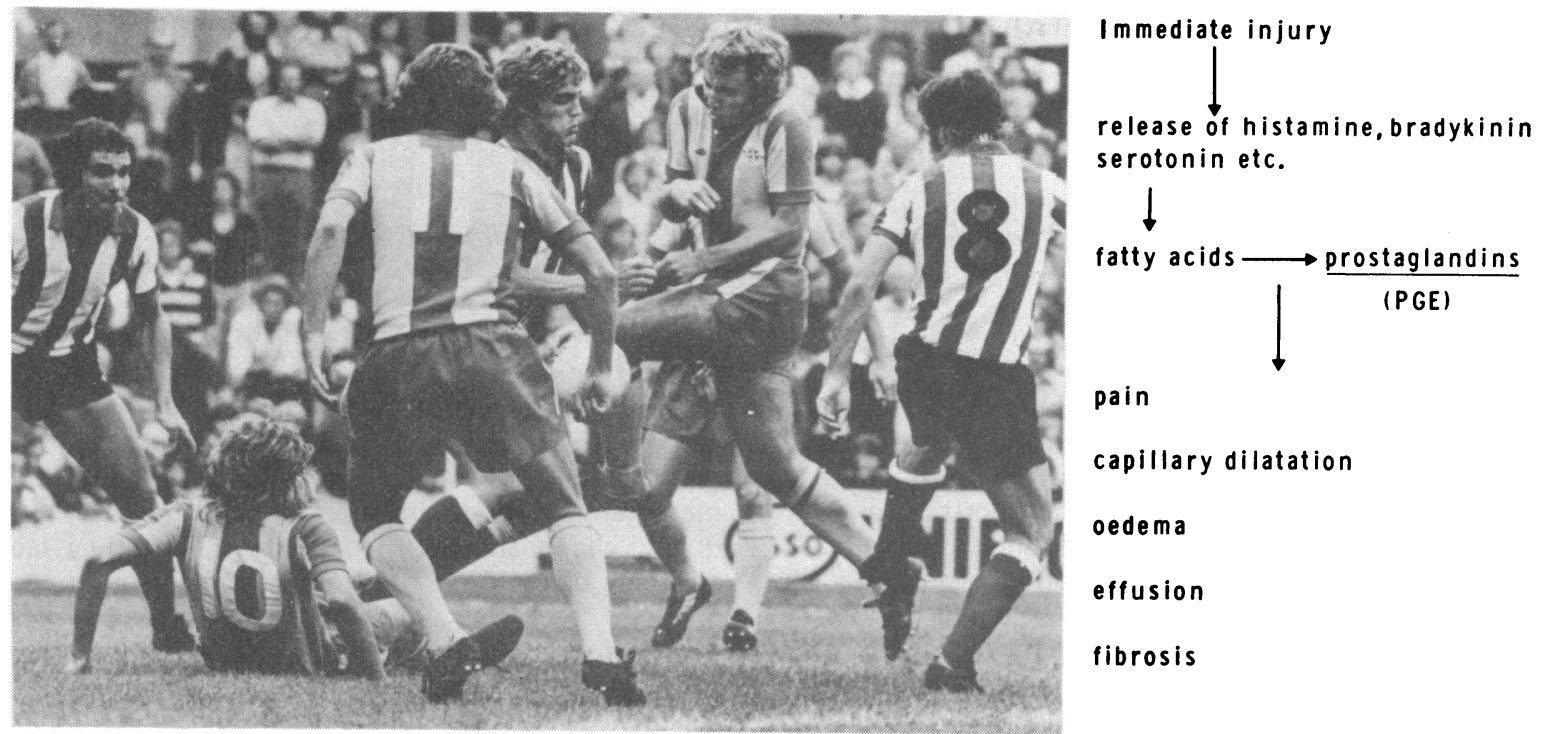
serotonin etc.

$\downarrow$

fatty acids $\longrightarrow$ prostaglandins

(PGE)

pain

capillary dilatation

oedema

effusion

fibrosis

Fig. 1. The stages of inflammation after soft tissue injury.

\section{References}

Adams, S. S., Bresloff, P., and Risdall, P. C. 1975. VIII European Rheum. Cong. suppl. 8: 1119.

Andersen, N. H., and Ramwell, P. W. 1974. Arch.Int.Med. 133: 30

Blumenkrantz, N., and Sondergaard, J. 1972. Nature 239: 246.

Buelvas, P. R. 1967. Abstr. IV Panamer.Congr. Rheum.; Excerpta Medica Foundation Int.Congr. Series. 143: 99.

Huskisson, E. C., Berry, H., Street, F. G., and Medhurst, H. E. 1973. Rheumatol. and Rehab. 12: 159.

Leclerc, F. P., and Autissier, D. 1969. Gaz.Hop. (Paris). 1: 31.

Muckle, D. S. 1974. Rheumatol. and Rehab. XIII: 141.

Vane, J. R. 1971. Nature 231: 232.

Zurier, R. B. 1974. Arch.Intern.Med. 133: 101. 